\title{
Gênero: \\ um ingrediente distintivo nas rotinas produtivas do jornalismo
}

\author{
Marcia Veiga \\ Universidade Federal do Rio Grande do Sul - marciaveiga2005@gmail.com \\ Jornalista, mestre e doutoranda em Comunicação e Informação \\ pela UFRGS, membro do Grupo de Pesquisa Estudos em Jornalismo \\ da Universidade do Vale do Rio dos Sinos - Unisinos. Vencedora do Prêmio \\ Adelmo Genro Filho 2011, na categoria Melhor Dissertação de Mestrado, \\ concedido pela Associação Brasileira de Pesquisadores em Jornalismo. \\ Selecionada no $1^{\circ}$ Prêmio Edital de Enfrentamento à Violência \\ Contra as Mulheres, concedido pela CAPES e Secretaria de Políticas \\ para as Mulheres da Presidência da República, no ano 2009, sendo \\ seu projeto de pesquisa o único selecionado da área da Comunicação \\ no Brasil, e resultou no financiamento de sua pesquisa de mestrado.
}

\section{Resumo}

Neste artigo, discuto alguns resultados da pesquisa realizada para dissertação de mestrado um estudo de newsmaking inspirado no método etnográfico, desenvolvido em três meses de observação na redação de um telejornal da RBS TV Porto Alegre. Para isso, resgato sucintamente o percurso teórico-metodológico que indica as bases sobre as quais este estudo se desenvolveu. Centro a discussão nos aspectos que levam a perceber os valores culturais hegemônicos em todo percurso de produção das notícias. Além disso, trago excertos do diário de campo na apresentação e análise de alguns dados que, entre outras coisas, levaram-me a concluir que gênero é um elemento distintivo nos modos do fazer jornalístico, bem como nas relações e hierarquias entre os profissionais e entre as próprias notícias.

\section{Palavras-chave}

Jornalismo; rotinas produtivas; gênero.

\section{Abstract}

In this article, I discuss some results of the research conducted for my masters' dissertation - a newsmaking study inspired by the ethnographical method, developed during three months of observation inside a broadcast newsroom of RBS TV Porto Alegre. For that, I succinctly present the theoretical and methodological course that indicate the bases on which this study was developed. I center the discussion on the aspects that leads to the perception of hegemonic cultural values throughout the process of producing the news. Besides, I introduce excerpts of the field journal in the presentation and analysis of some data that, among other things, lead me to the conclusion that gender is a distinctive element of the making of journalism as well as in the relations and hierarchies between professionals and between news themselves.

\section{Keywords}

Journalism; productive routines; gender. 


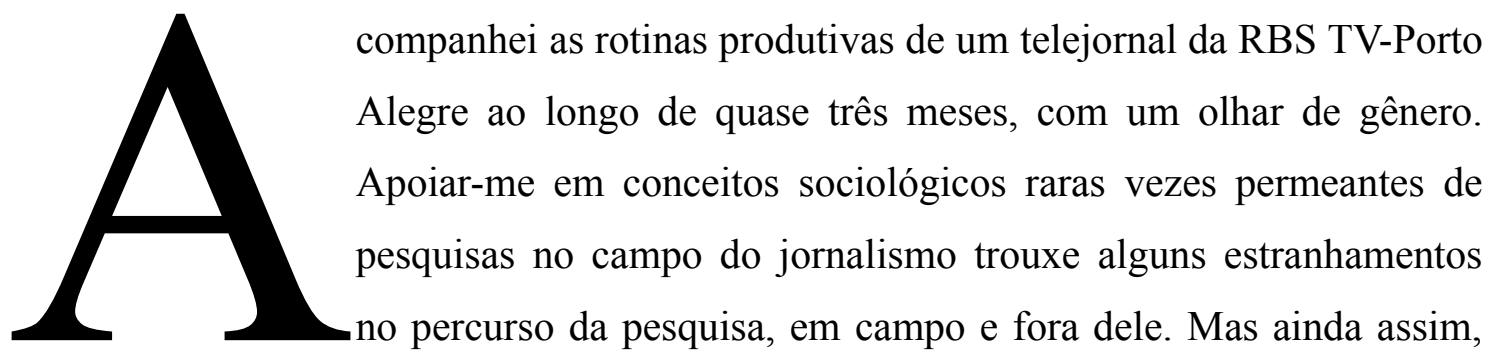
ao final, revelou-se um modo bastante interessante de compreender alguns valores, hierarquias de poder e de prestígio na cultura jornalística em consonância com a cultura hegemônica de nossa sociedade. Nesse sentido, o conceito de gênero utilizado contribuiu para pensar sobre as relações de poder e sistemas de desigualdades que constituem não apenas as relações entre profissionais e empresa, mas também como parte constituinte dos critérios de noticiabilidade do programa investigado. A escolha do método etnográfico para a realização de um estudo de newsmaking também se mostrou profícua para estas compreensões, em especial sobre a mescla complexa que dota de sentido a produção jornalística e suas interseções com a cultura de uma sociedade. Ao longo da pesquisa, desenvolvida com uso das técnicas da observação participante e descrição densa, as imbricações entre os valores culturais e profisssionais dos jornalistas apareciam como ingredientes no processo produtivo das notícias e serviam como elementos que norteavam respostas para algumas questões: o que estaria a orientar a ordem das notícias, as escolhas de determinadas matérias e de determinados profissionais em um programa? Quais elementos estariam presentes nas disputas? Quais as concepções de gênero dos jornalistas e em que medida permeiam as notícias?

Levando em conta a vasta produção de estudos que dão conta de uma sociologia do jornalismo, ao refletir sobre esse campo, apoiada também em conceitos que ajudam a pensar sobre produção de diferenças, desigualdades e poder, pude compreender que também naquela "tribo" os sistemas de valores dominantes da cultura social estavam imiscuídos como parte da cultura profissional e da identidade dos jornalistas. No caso das relações entre os profissionais, percebi que as atitudes e os atributos mais valorizados encontravam-se em consonância com os valores convencionalmente associados ao masculino, e deste modo mais próximos do poder e do prestígio. Naquele pequeno universo, os valores e a hierarquização de profissionais, de notícias e as demais escolhas durante a produção equiparavam-se à normatividade social vigente.

O que pretendo aqui discutir é o fato de que as concepções e os atributos de gênero dos jornalistas estão imiscuídos nos processos de produção e nas notícias, revelando que o próprio jornalismo é constituído de hierarquias de gênero, indicando 
uma ligação entre a cultura profissional e o plano de valores mais geral da sociedade. Essas (entre outras) constatações foram resultados da pesquisa, as quais mais especificamente me detenho a abordar neste artigo. $\mathrm{O}$ eixo da discussão proposta com base nesses resultados está centrado, fundamentalmente, no entendimento de que os jornalistas, no âmbito de suas identidades e exercício como profissionais, aparecem claramente como sujeitos constituídos por gênero. Os atributos de gênero aparecem como marcadores de distinção e como elementos que correspondem às posições que os mesmos ocupam, das quais os mesmos se investem ou pelo modo como são reconhecidos no universo de valores e hierarquias da empresa. E é sobre essa composição complexa que pretendo brevemente aqui discorrer, a partir dos dados e resultados obtidos. Importa ressaltar que os fragmentos de diário de campo serão utilizados no corpo do texto, trazendo em forma de pseudônimos os nomes de todos os envolvidos na pesquisa, a fim de proteger as identidades dos interlocutores.

\section{Das certezas que norteiam a sociedade e se tecem no e pelo jornalismo: perspectivas teóricas e metodológicas da pesquisa}

Não é difícil perceber, através dos meios de comunicação, e do jornalismo em particular, as normas e convenções sociais que orientam a normatividade em nossa cultura. Seja através dos dados que demonstram os marcadores sociais sobre os quais as desigualdades são manifestas, seja através dos parâmetros que nos dizem sobre o certo, o errado, o normal e o legítimo, cotidianamente a mídia nos serve como um dispositivo pedagógico (FISCHER, 2002) acerca dos comportamentos humanos. Filiada às teorias construcionistas, inspirada nos estudos de newsmaking, desejava compreender de que modo o jornalismo participava deste processo de produção simbólica, com foco em todo processo produtivo. Interessava-me conhecer a cultura daquela "tribo" e suas intersecções com a cultura da sociedade, indo além da análise dos discursos prontos, que já davam pistas de que havia um parâmetro normativo a orientar as realidades construídas pelas notícias. Através delas surgem receitas de como ser homem ou mulher, criança, idoso(a), bem sucedido(a), saudável, bonito(a), das formas corretas de exercício da sexualidade, bem como o processo continuado da forja dos sujeitos que "interessam" socialmente. E todas estas receitas são baseadas em alguns pressupostos histórica e culturalmente construídos como irrefutáveis, e deste modo participam dos conhecimentos sociais partilhados pelo jornalismo. 
O pressuposto de que os sujeitos nascem homens ou mulheres - e com isso têm seus gêneros orientados respectivamente para seus atributos equivalentes (homens/fortes, mulheres/sensíveis, por exemplo) - e de que são, essencialmente, heterossexuais, são algumas das "certezas" cotidianamente reafirmadas como inatas e que servem de sustentação para moldar as relações sociais, em um padrão que muitos estudiosos chamam de heteronormatividade (BUTLER, 2003a). Implícitos a estas conformações estão os parâmetros que dizem respeito a marcadores sociais hegemônicos, tais como gênero e classe, que constituem o centro a partir do qual as relações se organizam a priori. Esses atributos, tomados como parâmetros do normal para a constituição das regras que regem o social, segundo alguns teóricos, acabam por constituir uma hierarquia social excludente que pode ser compreendida por meio da imagem de uma pirâmide de distribuição do poder, cujo topo é formado pelo masculino hegemônico, e a base por atributos que remetem ao que se coloca no pólo oposto - o feminino (RUBIN, 1993).

O conhecimento social produzido pelo jornalismo (PARK, 2008; GENRO FILHO, 1987; MEDTISCH, 1992) encontra nos estudos de gênero um aporte teórico capaz de ajudar na compreensão sobre como as diferenças se transformam em desigualdades. Não apenas porque "gênero faz parte do sujeito, constituindo-o [o sujeito possui gênero e é diferenciado, reconhecido e valorado a partir dele]", mas porque "as diferentes instituições e práticas sociais são constituídas pelos gêneros e são, também, constituintes [e produtoras] dos gêneros" (LOURO, 1997, p. 25). Um olhar de gênero sobre o jornalismo envolve não apenas as mulheres, mas também os homens, e não restringe seu foco às diferenças entre os sexos biológicos ou aos papéis desempenhados por ambos os gêneros, abrangendo também as relações de poder generificadas que se estabelecem. Nesse sentido, cabe informar que a perspectiva teórica dos Estudos Feministas pós-estruturalistas foi adotada para pensar o conceito de gênero como algo que aproxima-nos

de abordagens muito mais amplas, que nos levam a considerar que as próprias instituições, os símbolos, as normas, os conhecimentos, as leis e as políticas de uma sociedade são constituídas e atravessadas por representações e pressupostos de feminino e masculino ao mesmo tempo que estão centralmente implicadas com sua produção, manutenção ou ressignificação (SCOTT, 1995; LOURO, 1997; MEYER, 2000b, apud MEYER, 2003, p. 16).

Nesse sentido, o conceito é utilizado "com referência não a limitações biológicas, mas sim [focalizando as] formas locais e específicas de relações sociais e 
Estudos em Jornalismo e Mídia - Vol. 9 № 2 - Julho a Dezembro de 2012

particularmente de desigualdade social (ROSALDO, 1995, p. 22). Gênero é entendido como "um elemento constitutivo de relações sociais fundadas sobre as diferenças percebidas entre os sexos, e o gênero é um primeiro modo de dar significado às relações de poder" (SCOTT, 1990, p. 14). As distinções de gênero não raro se transformam em relações desiguais entre o masculino e o feminino em todos os campos da vida social: nos corpos, nos discursos, nos conhecimentos, nas leis, nas práticas sociais, nas famílias, e até mesmo nas notícias, conforme pude perceber ao longo da pesquisa. É a partir dos símbolos culturais hegemônicos, produzidos nas instâncias de poder, que se operam os sentidos entendidos como legítimos sobre o que significam masculino e feminino, indicando, também, os lugares sociais destes. Nessa história, a produção do feminino esteve sempre associada ao que menos possui valor social em nossa sociedade, como a fragilidade, a sensibilidade, a passividade e a subordinação, sempre em relação ao seu oposto e centro normativo: o masculino, sinônimo de força, virilidade, próatividade, provimento, entre outros. E foi amparada nestas concepções de gênero e suas intersecções com as relações de poder que o jornalismo foi observado.

Para tal observação, desenvolvi a pesquisa de mestrado interessada em compreender quais as concepções de gênero (de masculino e de feminino) dos jornalistas e perceber se e de que modo elas participavam dos processos de produção das notícias. Ao longo de onze semanas ${ }^{\mathrm{i}}$, realizei um estudo de newsmaking, com base no método etnográfico, com uso das técnicas da observação participante e descrição densa, junto aos jornalistas de um programa ${ }^{\text {ii }}$ da RBS TV, na cidade de Porto Alegre, ao qual atribuí o pseudônimo Semanário. Observando o grupo formado por cinco jornalistas, e levando em conta os demais profissionais implicados nos processos produtivos das notíciasiii, procurava aprender sobre o complexo processo "que transforma matéria-prima (os acontecimentos) num produto (as notícias)" (TRAQUINA, 2004, p. 180) culturalmente (in)formativo.

Para conhecer o processo de construção das notícias, as quais são também modos de construção da realidade, é fundamental acompanhar empiricamente as rotinas produtivas. Assim, os jornalistas, responsáveis pela transformação dos acontecimentos em notícias, são centrais. São eles os elementos humanos, capazes de produzir significados a partir dos sentidos que determinados fatos lhes geram ou não; são eles os responsáveis por dar "vida" ao acontecimento pelo reconhecimento dos valores capazes de transformá-lo em notícia. Entretanto, os valores-notícia se revelaram intrinsecamente relacionados com os valores sociais, culturais e subjetivos dos jornalistas. Do mesmo 
modo, as relações entre estes profissionais se mostraram marcadas pela distinção de atributos de gênero (e também de raça, de classe, de geração e de religião), com ingerência direta nos modos de produção das notícias e também nas relações hierárquicas, de poder e de prestígio entre eles. Estas distinções tinham por base as convenções sociais hegemônicas de gênero - tudo que predominantemente associamos ao masculino e ao feminino em nossa cultura.

A observação das rotinas produtivas resultou numa interessante compreensão não só das convenções hegemônicas que estavam a orientar o processo e a produção das notícias, marcadas pelas visões de mundo dos jornalistas, que acabavam por servir como discursos a partir dos quais os grupos ou as classes constroem uma
imagem das vidas, significados, práticas e valores de outros grupos
ou classes sociais e sobre a sua situação com relação ao quesito
globalidade. [...] O que tem sido classificado e representado localiza-
se dentro de uma ordem bem reconhecida. (ALSINA, 2009, p. 71-72,
grifo do autor)

Foi igualmente possível compreender o quanto estas convenções estavam consensuadas pelos jornalistas na cultura profissional, a ponto de refletirem também nas relações entre eles. Os atributos de gênero dos jornalistas apareceram como marcadores de distinção e como elementos que correspondem às posições que os mesmos ocupavam, das quais os mesmos se investiam ou pelo modo como eram reconhecidos. É com foco nestas distinções, em que as concepções sobre o masculino e feminino participavam intrinsecamente, que passo a discutir alguns dados da pesquisa.

\section{Sobre alguns dados de campo: as relações de gênero, os lugares de prestígio e poder entre os jornalistas}

As relações de gênero e de poder são aqui entendidas quase como sinônimos, uma vez que não apenas estão em jogo os sexos dos interlocutores, mas fundamentalmente as posturas e os valores postos nas disputas e que pesavam nas decisões e no delineamento das matérias. No processo de produção das notícias, pude perceber o quanto os sujeitos envolvidos eram constituídos e reconhecidos por características de gênero e davam conta de posturas mais ou menos valorizadas. Tanto as características pessoais quanto as posições de sujeito (sexo, geração, classe, atributos de gênero, entre outras) e as posturas em grupo revelavam as relações de poder em jogo, assim como os atributos de gênero mais e menos valorados e que incidiam na 
hierarquização dos profissionais e nas escolhas como um todo. O campo revelou que gênero era constitutivo dos papéis exercidos pelos (e esperados dos) profissionais, das relações e estruturas hierárquicas e de poder, e das visões de mundo que estavam a orientar a produção das notícias em todas as suas instâncias.

No caso das relações entre eles, pude perceber que as atitudes e atributos valorados estavam em consonância com valores hegemônicos de gênero. Ou seja, neste pequeno universo, os valores e as estruturas de hierarquização equiparavam-se à normatividade social vigente. Atributos tidos como masculinos (atividade, força, coragem, imposição, impulso, competição, seriedade, autonomia, etc.) e também os relacionados à geração (nesse caso também contando o tempo de experiência de trabalho) e classe-média, entre outros, estavam hierarquicamente mais próximos do poder.

Um exemplo de como os atributos de gênero convencionalmente associados ao masculino estavam bem valorados nas estruturas hierárquicas da empresa é o estimável perfil do jornalista investigativo. As características associadas a esse profissional eram reveladoras dos atributos de mais-valia: “caça de furos", coragem, iniciativa, autonomia, risco, conquista. Não apenas quem se investia deste papel ou possuía as características consideradas necessárias para a realização deste tipo de matérias gozava de prestígio e relevância na hierarquia da empresa, mas as matérias cujos atributos também estivessem relacionados ao masculino - em especial o "furo" - eram tidas como centrais.

No grupo pesquisado, um dos principais e mais cultuados repórteres era Fábio Fonseca. Com cerca de 40 anos, era o jornalista responsável pela maioria das matérias investigativas e de denúncia, que eram exibidas por todos os telejornais da empresa. Diferente dos demais repórteres, subordinados às pautas e escala de horários determinadas pela chefia de produção, bem como às disponibilidades de equipes e equipamentos, Fábio tinha autonomia, possuía suas fontes, fazia seus próprios contatos, tinha veículos e equipamentos exclusivos e diferenciados à sua disposição, possuía rotinas e horários próprios, e não estava submetido nem mesmo à escala dos plantões. Sua atuação geralmente envolvia a denúncia de escândalos de cunho político e policial, com caráter inédito e revelador. Suas matérias não eram produzidas de forma restrita ao estado, visando também à veiculação em nível nacional, nos principais telejornais da Rede Globo.

Gozando de status na empresa e entre os colegas, Fábio se investia deste prestígio em seus comportamentos junto ao grupo, e muitas vezes era temido e causava 
constrangimentos àqueles que em alguma medida se envolviam na edição das matérias que produzia. Trago alguns fragmentos para ilustrar o prestígio de Fábio:

[redação, ilha Semanário] Fábio chega e vai falar com Antonio. Antonio pergunta se ele (Fábio) vai gravar um off ou se vai ser cabeça. Fábio diz: pela novidade da coisa, acho que tem que ser cabeça. Antonio pergunta para Fábio: vamos furar eles [a concorrência] hoje? Fábio responde: vamos, porque o cara me garantiu que não falou com ninguém ainda, mas amanhã o juiz vai falar (Diário de Campo, doravante DC, 03/05/09).

[reunião de pauta] Antonio pergunta: E o Fonseca, o que será que tem pra nós? Kauã chama Fábio Fonseca, que está na redação. Quando Fábio entra na sala, Antonio de imediato pergunta pra ele: $\boldsymbol{o}$ que tu tens pra nós do Semanário? Fábio responde: nada ainda, tudo em processo. Depois fala rindo: só se me der como manchete e a Quitéria chamar na cabeça do programa dizendo 'O Fábio está por aqui' (DC, 09/03/09).

Em vários momentos a figura deste jornalista na redação me chamava atenção, e não apenas quando o mesmo estava presente. Seu nome era invocado em diversas situações em que buscavam matérias "quentes", "fortes", de "impacto". Era como se o privilégio de fazer algo com $100 \%$ de chances de alcançar audiência lhe fosse característico.

[Reunião de pauta Semanário]: Kátia pergunta se precisa ter assunto forte [no programa], e Quitéria responde: Precisa. Quitéria pega o telefone, liga para Fábio Fonseca e pergunta: o que tu tens pra gente abrir o programa? Uma coisa forte, que só tu sabe fazer. (DC, 24/03/09)

Mas não apenas este profissional demonstrava as características mais valoradas que compunham um perfil pessoal e de notícias cujos atributos são masculinos. Outros jornalistas, como Samuel, apresentador do Semanário, foram identificados no campo com tais atributos. Muitas vezes o poder não estava diretamente associado a uma chefia - por vezes até mesmo se sobrepunha a tal função, como no caso de Samuel e Fábio mas igualmente representava prestígio, regalias, autonomia, poder de persuasão e de decisão nas disputas e junto às instâncias mais altas da empresa. Kátia, que no período da pesquisa revezava interinamente a função de editora-chefe no Semanário, declarou mais explicitamente as distinções de gênero nas estruturas da empresa quando the pedi suas impressões sobre ocupar o cargo de chefia, no qual a percebia muitas vezes desconfortável:

Pergunto a Kátia sobre suas impressões no cargo de chefe, e se ela sente que há diferença por ser mulher; e ela me diz que sim, inclusive no salário. Kátia me diz que não pode provar, mas que acredita que as mulheres ganham menos que os homens na empresa. Ela me diz que há uma cultura no Brasil e na empresa de 
valorização de quem é autoritário, e que ela não consegue ser assim. Conta que já pensou em se violentar e tentar fazer isso, mas que não consegue. Explica que sua posição [como editora-chefe interina] é muito complicada porque cada um espera e olha para ela de modos diferentes, seja como mãe, como parceira, como alguém para fazer sexo. Ela se refere a Samuel como um "espírito livre", o que me faz entender, pelo que ela diz e pelo que percebo nas relações dele com ela, que ele é um profissional autônomo, que faz o que quer (e quando quer), alguém que não reconheça nela autoridade para o cargo. Kátia me diz que sente machismo na empresa. Diz que há muitas diferenças entre os profissionais, inclusive de classe. Explica que até mesmo o lugar onde os carros são estacionados é um elemento de diferenciação. Me conta que só ganha bem quem é chefe, e que ela, nessa substituição, não recebe mais por isso, apesar de ter mais responsabilidades, pois não é oficializada. (DC, 06/04/09)

O que Kátia declarou na conversa pude perceber na maioria das vezes em que ela estava como editora-chefe interina. Sua atuação se dava num sentido horizontal, de escuta, de diálogo. Por diversas vezes ela foi confrontada e contrariada em suas proposições por Samuel - geralmente protagonista de disputas e, na maioria absoluta das vezes, vencedor destas. O desconforto, as inseguranças geradas pelas disputas e relutâncias em acolher o que era por ela proposto visivelmente fragilizavam Kátia diante dos demais. Ela acabou saindo do programa. No anúncio de sua saída, claramente verbalizou o peso da influência de Samuel, já percebida por mim nas relações entre eles:

Explico para Kátia que meu campo está se encaminhando para o fim, e que estava querendo ver a possibilidade de acompanhar alguma matéria, e que essa semana pelo jeito estava difícil. Para minha surpresa, ela me diz que está saindo do programa também. Eu pergunto o que houve, e ela me diz que está indo para outro programa. E completa: Samuel me disse que não queria que eu saísse, e por isso cheguei a pensar em mudar de ideia. (DC 23, 13/04/09)

Além das relações de poder entre os participantes, as disputas travadas no âmbito das decisões e em todo o processo de escolhas durante a produção das notícias estavam permeadas de concepções de gênero. $\mathrm{O}$ elo do processo se revelava através dos valores-notícia que, quando acionados, davam conta da conjunção entre os valores pessoais, profissionais e culturais que os envolvidos no processo entendiam como capazes de atrair (gerar sentido) ao público. Esses valores em muito se interseccionam com os atributos pessoais sob os quais os profissionais se estabeleciam junto aos demais, ou seja, cada profissional se postava e era percebido com atributos de gênero, classe e geração que davam contornos do lugar de onde falavam e das escutas que geravam (ou não) junto ao grupo. Estas características pessoais se relacionavam com as escolhas e as propostas de pauta (e modos de fazer) e entravam em disputa para as 
decisões. Nos demais setores do processo produtivo, também percebi que cada profissional elencava e atribuía valores subjetivos a cada uma das partes pelas quais eram responsáveis por executar e, de um modo prevalente, eram valores sociais hegemônicos, em especial de gênero e sexualidade.

O Semanário possuía uma identidade formada pelas características que lhe eram atribuídas e, de um modo geral, havia uma consonância sobre seu perfil e o estilo das matérias que o constituíam. Segundo lugar no IBOPE entre os programas jornalísticos da empresa, segundo me informou o antigo diretor de telejornalismo, era considerado, pela empresa e por seus integrantes, como o programa número um (Antonio, DC, 05/04/09), que tem o apelo de um programa popular, com audiência formada pelo público adulto, masculino, das classes sociais $A, B, C$ (Antonio, DC, 05/04/09). Havia um formato já consolidado e um estilo a perseguir.

O Semanário era composto por três blocos ${ }^{\mathrm{iv}}$, e as notícias eram pensadas e hierarquizadas de acordo com algumas características desejadas para que o programa obtivesse e segurasse audiência até o final. A pauta, portanto, era concebida a partir de três principais tipos de notícias. Entre elas, em cada bloco, pequenas notas cobertas $^{\mathrm{v}}$ com assuntos factuais produzidos no dia, na capital e em diversas cidades do interior, chamadas de notão. Mas os notões, normalmente, não eram objeto da reunião de pauta, apesar de serem produzidos pelos editores de texto do Semanário, na capital, no dia do programa.

Para abrir o programa, bloco considerado mais importante, buscavam matérias inéditas, fortes, de impacto. Matérias que não possuíssem esses atributos preferenciais, e relacionados ao que convencionalmente se associa ao masculino (forte, impacto, denúncia etc.), não eram cogitadas para este bloco:

[reunião de pauta] $\mathrm{Na}$ fase da avaliação, comentam que Denis não tinha gostado da matéria da modelo dos pés necrosados ter sido a de abertura, e que tinha criticado a ordem das matérias. Antonio diz que argumentou com Denis que foram feitas várias tentativas para abertura, mas que a melhor tinha sido essa. Quitéria também justifica a escolha e diz: $\boldsymbol{A}$ das mulheres é que não dava pra entrar primeiro, era muito frufru (DC, 09/03/09).

O terceiro e último bloco previa reportagens leves, e essas não eram tão valorizadas quanto as do primeiro, mas ainda assim concebidas levando em conta a responsabilidade de fechar o programa de uma forma apropriada para o horário noturno e capaz de assegurar a audiência na fase final. Fechamento com matéria de impacto, no Semanário, apenas quando surgissem notícias de última hora, ao estilo "furo", no 
horário mais próximo do final do programa. Já no segundo bloco, em geral, qualquer matéria de comportamento inédita ou "repaginada" poderia entrar, pois se tratava do bloco com a menor exigência.

$\mathrm{O}$ primeiro e o terceiro blocos eram preferencialmente reservados às matérias produzidas pelos dois apresentadores (Samuel e Quitéria), e qualquer um deles, ou mesmo outro repórter especial da empresa que trouxesse uma matéria inusitada, inovadora, de impacto, denunciativa ou forte, teria assegurado o primeiro bloco. Samuel, geralmente era quem sugeria as pautas das matérias do primeiro bloco, e muitas vezes era quem as realizava. As pautas sugeridas e realizadas por ele, em geral, não passavam por discussão no grupo, que era tão somente informado. As reportagens do segundo bloco contavam com a participação de outros repórteres, além de algumas assinadas por Quitéria e, mais raramente, por Samuel. No terceiro bloco, prevaleciam as reportagens realizadas e, em grande parte, sugeridas por Quitéria, com a contribuição do grupo desde a concepção (pauta). Cada notícia produzida, visando a um dos blocos, estava permeada de valores-notícia constituídos de atributos como, por exemplo, denúncia/forte; comportamento/leve. Com o tempo consegui identificar o que considero o principal valor-notícia do Semanário, o que prevalecia nos processos decisórios, o que era capaz de tornar um fato notícia, bem como servir de critério para seus respectivos repórteres: a emoção.

A emoção era um valor invocado como capaz de gerar sentido não só para atrair a audiência, mas principalmente porque dizia respeito ao que fazia sentido a seus produtores. Na maioria das disputas entre fatos que poderiam tornar-se notícia, ou entre aqueles que deveriam abrir o programa, e até mesmo na definição dos contornos da matéria e do perfil do profissional para fazê-la, a "emoção" era o critério principal. Em diversas situações no campo este valor foi invocado como determinante das escolhas, das sugestões e da hierarquia das pautas e das notícias, o que me levou a investigar quais elementos poderiam caracterizar tal mobilizador. Procurei identificar, nos discursos e nas práticas de meus interlocutores, os valores presentes em cada uma destas sugestões e nos seus processos de feitura. Em especial, tentei perceber as concepções e valores de gênero imiscuídos nos processo produtivos e nas notícias prontas, a fim de conhecer de que modo eram articulados e incidiam nas escolhas e decisões. Isso se fez necessário porque entendo que são justamente os valores-notícia aqueles que conjugam tanto os valores subjetivos quanto os culturais e profissionais que são acionados e tomados como parâmetro para que um fato adquira status de noticia. 
Tomando as matérias propostas e pensadas pelos (e também para os) principais repórteres do programa, verifiquei que havia dois modos prevalentes na forma como a emoção aparecia como um valor. De um lado estavam as emoções derivadas de matérias de cunho investigativo, denunciativo, de risco, de competição (como o futebol), relacionadas à (i)legalidade, de alta cultura, poder, entre outras. E estes vieses caracterizavam as matérias preferenciais, consideradas "fortes", "de peso", "quentes", buscadas para a abertura e impacto do programa. De outro, as matérias cuja emoção estava associada a valores como proteção, fragilidade, brincadeira, piadas, solidariedade, percebidas como leves, lúdicas, indicadas para entreter e não exigir reflexões. Estes vieses também definiam os profissionais atuantes nas matérias como repórteres. Para as notícias relacionadas ao investigativo, ao risco, etc., os profissionais propostos eram exclusivamente do sexo masculino, e com determinadas características de gênero consolidadas e reconhecidas por seus pares - ou seja, mulheres, ou mesmo homens que não possuíssem características reconhecidamente associadas aos atributos masculinos já mencionados, não eram pensados como alternativa capaz de executar tais matérias, como se percebe na passagem que segue.

[reunião de pauta] Samuel sugere que se faça uma matéria que foi feita há muitos anos, pelo Claudio Bello. A matéria seria sobre os parques à noite. Sugere que seja feita por um repórter com perfil de polícia, e sugere que seja o Rios. Kauã diz que acha que não precisa ser feita por um repórter com perfil de polícia, acha que poderia ser feito por outro. Samuel diz que precisa ter perfil de polícia, porque à noite, nos parques, o que tem são gays, viciados e traficantes. Quitéria diz que é melhor ter perfil policial porque esse tipo de repórter saca coisas que outro não sacam. [...] Eles ficam discutindo sobre qual repórter poderia fazer a matéria dos parques. Falam o tempo todo sobre conseguir um repórter homem. Quitéria diz que Alvim é bom para matérias de brincadeira, Kauã diz que Lúcio é pra fazer matérias com um tratado de filosofia. Cogitam Fábio Fonseca, mas alguém diz que ele não faria essa matéria (por não ser inédita). Quitéria chega a sugerir quem sabe uma mulher?, mas a idéia não perdura. Kauã chegou a sugerir Bruna Esteves, mas Quitéria questiona: por que tu acha que ela seria uma repórter pra isso? Ela é uma repórter normal, de geral. [...] (DC, 20/04/09).

Um perfil de polícia, um repórter corajoso, capaz de fazer uma matéria forte, claramente tinha de reunir atributos afins e, para tanto, um repórter homem parecia ser a solução mais óbvia, inicialmente. E é nesse dia que descubro que o que estava implícito nessa escolha eram atributos de gênero e não o sexo biológico dos repórteres, pois nem todos os "homens" da redação apresentavam esses atributos. Alvim e Lúcio, certamente, não. Carlos Rios e Fábio Fonseca, sim. Do mesmo modo, as matérias relativas aos 
Estudos em Jornalismo e Mídia - Vol. 9 № 2 - Julho a Dezembro de 2012

dramas sociais mais gerais, as "softnews", as brincadeiras e as piadas, eram pensadas para o sexo feminino.

$\mathrm{Na}$ produção das matérias, desde o surgimento, os valores subjetivos eram acionados e delineavam seus contornos. Passado o processo de definição do perfil da notícia (e do profissional), o restante do percurso também estava permeado de escolhas que levavam em conta esses valores culturais e que do mesmo modo influenciavam cada processo de escolha e de decisão. Desse modo, conforme pude me deter e melhor analisar em minha dissertação, também as convenções sociais hegemônicas serviam como parâmetro acerca dos juízos de valor que incidiam nas decisões em todo percurso de construção das notícias. Notícias crivadas de suposições acerca do que/quem é certo, normal ou legítimo foram produzidas e refletiam que a heteronormatividade era o padrão a orientar os valores culturais e profissionais dos jornalistas.

\section{Considerações finais}

O jornalismo foi observado e pensado com um olhar de gênero. Durante todo o processo, procurei analisar as concepções de gênero dos jornalistas com o objetivo de perceber se, e de que maneira, elas atravessavam a produção de notícias e contribuíam para a reprodução, manutenção, ressignificação ou transformação de padrões de desigualdade. $\mathrm{Na}$ hierarquia de valores e posições profissionais, percebi que o prestígio e o poder decorriam de um processo complexo, para além da simples competência profissional, e tinham relação também com a adequação dos sujeitos a determinados perfis, cujos atributos mais valorizados estavam em consonância com aqueles majoritariamente associados ao masculino. O masculino, parte das características idealizadas nas posturas profissionais, não era exclusividade dos sujeitos institucionalmente investidos nas estruturas de poder, mas indicativo de quem um dia poderia chegar mais próximo do (ou ao) topo da hierarquia. O mapa das relações de gênero, poder e prestígio apontaram para um tipo de estrutura que revelou uma similaridade com os modos como gênero e poder se estabelecem e se organizam nas relações sociais de forma geral. Ou seja, os atributos de gênero mais valorizados na hierarquia do programa, interseccionados com os marcadores de classe e geração, entre outros, correspondiam aos atributos e marcadores mais valorizados na heteronormatividade.

Analisando os valores e as concepções de gênero dos jornalistas, o estudo revelou uma relação direta entre o perfil do profissional e o tipo de notícia que este iria 
produzir, e que nesta relação intrínseca gênero era um elemento pervasivo ${ }^{\text {vi }}$ e determinante. Esta percepção se deu também por serem as notícias igualmente hierarquizadas numa escala de valores relacionadas aos atributos convencionais de gênero (fortes/leves; sérias/lúdicas; risco/cuidado, etc.). Assim, entre as pautas, como entre os repórteres, havia uma hierarquia de valores correspondentes, e as concepções de gênero estavam presentes na idealização das matérias, bem como permeavam as escolhas dos jornalistas que iriam realizá-las. As próprias notícias resultavam em discursos crivados de suposições acerca do que é normal, legítimo e correto em nossa sociedade segundo a heteronormatividade. Portanto, a reprodução desse padrão normativo apareceu como um dos saberes cotidianos que orientam e se orientam na cultura e fazem parte do acervo dos conhecimentos socialmente construídos e culturalmente legitimados que ajudam a informar os sujeitos (e também os jornalistas) na contemporaneidade, através do (e no) jornalismo.

Essas, entre outras percepções obtidas na pesquisa, ajudam na reflexão acerca de como o jornalismo participa na formação de valores e na reprodução de relações de poder e produção de desigualdades que se fundam na cultura, incidindo não apenas nas relações entre os membros da "tribo", mas igualmente nos mapas de significados que resultam em desigualdades sociais. A investigação num micro-universo como uma redação de jornalismo, deste modo, pode nos dizer muito sobre as produções de sentido e de valores que participam da cultura geral de uma sociedade e nos dar pistas de como incidir nos modos de transformação destas realidades. 


\section{Referências}

ALSINA, Miguel Rodrigo. A construção da notícia. Petrópolis, RJ: Vozes, 2009.

BUTLER, Judith. Problemas de gênero - feminismo e subversão da identidade. Rio de Janeiro: Civilização Brasileira, 2003a.

FISCHER, Rosa Maria Bueno. O dispositivo pedagógico da mídia. Modos de educar na (e pela) TV. Revista Educação e Pesquisa, São Paulo, v.28, n.1, p. 151-162, jan./jun. 2002.

GENRO FILHO, Adelmo. O segredo da pirâmide: para uma teoria marxista do jornalismo. 1987. Documento digitalizado, disponível em http://www.adelmo.com.br/index3.htm

LOURO, Guacira Lopes. Gênero, sexualidade e educação. Uma perspectiva pós-estruturalista. Petrópolis, RJ: Vozes, 1997.

MEDITSCH, Eduardo. O jornalismo é uma forma de conhecimento? Documento digitalizado, disponível em www.bocc.uff.br/pag/meditsch-eduardo-jornalismo-conhecimento.pdf

MEYER, Dagmar Estermann. Gênero e educação: teoria e política. In: LOURO, Guacira Lopes; NECKEL, Jane Felipe; GOELLNER, Silvana (org). Corpo, gênero e sexualidade: um debate contemporâneo na educação. Petrópolis, RJ: Vozes, 2003. p. 9 - 27

PARK, Robert E. A notícia como forma de conhecimento: um capítulo dentro da sociologia do conhecimento. In: BERGER, Christa, MAROCCO, Beatriz (Org.). A era glacial do jornalismo. Teorias sociais da imprensa. Porto Alegre: Sulina, 2008.

ROSALDO, Michelle. O uso e o abuso da antropologia: reflexões sobre o feminismo e o entendimento intercultural. In: Revista Horizontes Antropológicos. Dossiê Gênero, Ano 1, nº 1, Porto Alegre, 1995.

RUBIN, Gayle. Thinking Sex: Notes for a Radical Theory of the Politics of Sexuality, In: ABELOVE, Henry; BARALE, Michèle e HALPERIN, David. (eds.) The Lesbian and Gay Studies Reader. Nova York: Routledge, 1993.

SCOTT, Joan. Gênero: uma categoria útil de análise histórica. In: Educação e realidade, Porto Alegre. p. 5-22. "jul/dez. 1990".

TRAQUINA, Nelson. Teorias do Jornalismo, porque as notícias são como são. Volume 1. Florianópolis: Insular, 2004. 
${ }^{\text {i }}$ Realizada no período de 05 de março a 18 de maio de 2009.

${ }^{\text {ii }} \mathrm{O}$ nome do programa, bem como dos interlocutores da pesquisa foram substituídos por pseudônimos a fim de proteger a identidade das pessoas.

iii Diretores, chefes de redação e de produção, setores operacionais, editores de imagem, etc.

${ }^{i v}$ Um telejornal é dividido em partes, e bloco é a nomenclatura utilizada para se referir a cada uma dessas partes.

${ }^{\vee}$ Nota coberta é uma nota cuja "cabeça" é lida pelo apresentador e o texto seguinte é coberto com imagens. Esta nota pode ser gravada ou ao vivo.

vi O termo pervasivo, encontrado em textos da literatura sobre gênero, é um termo traduzido da palavra em inglês "pervasive", que significa: que penetra; difuso; penetrante.

Este artigo e todo o conteúdo da Estudos em Jornalismo e Mídia estão disponíveis em http://www.periodicos.ufsc.br/index.php/jornalismo/index

Estudos em Jornalismo e Mídia está sob a Licença Creative Commons. 